\title{
Solid-State Synthesis, Characterization, and Biological Activity of the Bioinorganic Complex of Aspartic Acid and Arsenic Triiodide
}

\author{
Guo-Qing Zhong, ${ }^{1}$ Wen-Wei Zhong, ${ }^{2}$ Rong-Rong Jia, ${ }^{3}$ and Yu-Qing Jia ${ }^{3}$ \\ ${ }^{1}$ State Key Laboratory Cultivation Base for Nonmetal Composite and Functional Materials, \\ School of Material Science and Engineering, Southwest University of Science and Technology, Mianyang 621010, China \\ ${ }^{2}$ College of Life Sciences, Sichuan University, Chengdu 610064, China \\ ${ }^{3}$ Department of Chemistry, East China University of Science and Technology, Shanghai 200237, China
}

Correspondence should be addressed to Guo-Qing Zhong; zgq316@163.com

Received 2 May 2013; Revised 24 July 2013; Accepted 24 July 2013

Academic Editor: Henryk Kozlowski

Copyright (c) 2013 Guo-Qing Zhong et al. This is an open access article distributed under the Creative Commons Attribution License, which permits unrestricted use, distribution, and reproduction in any medium, provided the original work is properly cited.

\begin{abstract}
The bioinorganic complex of aspartic acid and arsenic triiodide was synthesized by a solid-state reaction at room temperature. The formula of the complex is $\mathrm{AsI}_{3}\left[\mathrm{HOOCCH}{ }_{2} \mathrm{CH}\left(\mathrm{NH}_{2}\right) \mathrm{COOH}\right]_{2.5}$. The crystal structure of the complex belongs to monoclinic system with lattice parameters: $a=1.0019 \mathrm{~nm}, b=1.5118 \mathrm{~nm}, c=2.1971 \mathrm{~nm}$, and $\beta=100.28^{\circ}$. The infrared spectra can demonstrate the complex formation between the arsenic ion and aspartic acid, and the complex may be a dimer with bridge structure. The result of primary biological test indicates that the complex possesses better biological activity for the HL-60 cells of the leukemia than arsenic triiodide.
\end{abstract}

\section{Introduction}

Arsenical compounds are toxicoid and hazardous materials. But the oxide and sulfide of arsenic can be used as the medicaments in the traditional Chinese medicine. Potassium arsenite was first reported for leukaemia treatment in 1865. Indeed, the main group metal elements, such as arsenic, antimony, and bismuth, can possess not only toxicity but also a certain biologic or medicinal function. For example, some compounds of arsenic, antimony, and bismuth can have good cytotoxicity and antitumor activities [1-5]. Nowadays, based on the gradually understood characteristics of these elements, many arsenic, antimony, and bismuth compounds have been synthesized and some have clinical and health applications. Currently, the major medicinal use of the compounds is focussed in two fields: antimicrobial and anticancer. Pharmacological applications of the inorganic complexes of the metal ion and organic ligands have also been reported $[6,7]$. In particular, the arsenic trioxide has appreciable biological activity for the cell line of acute promyelocytic leukemia (APL) [8-11], but the amount of arsenic trioxide must be controlled strictly in clinical therapy because of high toxicity. The investigation of arsenic interactions with potential targeting biomolecules, including amino acids, peptides, proteins, and enzymes, will lead to understanding of the mechanism of action of these complexes and in turn to the further application in medicine. Thus, seeking arsenical medicament with high curative effect and low toxicity is urgent to clinical therapy of leukemia. Some complexes of arsenic have been reported [12, 13].

There are always the natural amino acids in the human body. A lot of bioinorganic complexes of the natural amino acids and various transition metal ions have been prepared. However, the chemistry of natural amino acids of main group elements is less widely explored than that of transition metals, in particular the synthesis, structures, and biological activities of arsenic (III) complexes with natural amino acids. Therefore, to prepare the complexes of the arsenic and natural amino acids and to study the biologic activity of these complexes will be very interesting not only for the biologic chemistry of main group metal elements but also for the 
medicinal application of the amino acid complexes. Some amino acid or peptide complexes of antimony and bismuth have been synthesized by a direct solid-solid reaction [1417]. Aspartic acid is one of the natural amino acids in the human body. We find that the aspartic acid complex of arsenic can be synthesized very easily through a direct solid-solid reaction of the aspartic acid and arsenic triiodide powders. The characterizations can demonstrate the complex formation between the arsenic ion and aspartic acid. In particular, the primary biological test shows that the complex possesses larger inhibition rate on the growth of the HL-60 cells of the leukemia than arsenic triiodide.

\section{Materials and Methods}

All the chemicals used in the experiments are analytical reagents as received from commercial sources and without further purification. First, weigh $1.00 \mathrm{~g}$ aspartic acid and $1.36 \mathrm{~g} \mathrm{AsI}_{3}$ and very well mix up the two reactants together in an agate mortar. The molar ratio of $\mathrm{AsI}_{3}$ to $\mathrm{HOOCCH}_{2} \mathrm{CH}\left(\mathrm{NH}_{2}\right) \mathrm{COOH}$ is $1.0: 2.5$. Then, the mixture was grinded carefully. At first, the color of the mixture was orange and then became yellow. This indicated that the reaction did happen. The reaction was conducted in grinding at room temperature for $6 \mathrm{~h}$. The resultant was washed repeatedly by dehydrated ethanol. Last, the resultant was dried at $40^{\circ} \mathrm{C}$ in a vacuum drying oven for $4 \mathrm{~h}$. The yield of the complex was $95.8 \%$. The resultant is the yellowish powder. Unlike arsenic triiodide, the resultant does not show appreciable moisture.

The contents of carbon, hydrogen, and nitrogen in the resultant were determined by an Elementar Vario EL III elemental analyzer. The content of arsenic in the resultant was measured on a TJA IRIS 1000 ICP-AES analyzer. The analyses results are C (calcd. 15.23\%, found. 15.29\%), H (calcd. 2.24\%, found. 2.37\%), $\mathrm{N}$ (calcd. 4.44\%, found. 4.59\%), and As (calcd. $9.50 \%$, found. 9.38\%). This shows that the possible formula of the resultant will be $\mathrm{AsI}_{3}\left[\mathrm{HOOCCH}{ }_{2} \mathrm{CH}\left(\mathrm{NH}_{2}\right) \mathrm{COOH}\right]_{2.5}$. We find that the complex with 1.0:3.0 molar ratio of $\mathrm{AsI}_{3}$ to $\mathrm{HOOCCH}_{2} \mathrm{CH}\left(\mathrm{NH}_{2}\right) \mathrm{COOH}$ cannot be prepared by the same method.

To characterize if the resultant was a single-phase compound, the powder X-ray diffraction pattern of the resultant was recorded by a Rigaku D/max-YB X-ray diffractometer, $\mathrm{Cu} \mathrm{K}_{\alpha 1}$ radiation, and $\mathrm{Ni}$ filter, and scanning rate was $2^{\circ}(2 \theta) \mathrm{min}^{-1}$ at room temperature $(\lambda=0.154056 \mathrm{~nm})$. The powder X-ray diffraction pattern of the resultant is shown in Figure 1. The results of indexing to the powder X-ray diffraction pattern are listed in Table 1 . The infrared spectrum of the resultant was measured by a Nicolet 5SXC spectrometer and the potassium bromide disk technique. The infrared spectrum of the complex in the range from $400 \mathrm{~cm}^{-1}$ to $4000 \mathrm{~cm}^{-1}$ is shown in Figure 2.

The HL-60 cell line is from Shanghai Institute of Biochemistry and Cell Biology. The MTT (3-(4,5-dimethylthiazol-2-yl)-2,5-diphenyltetrazolium bromide) colorimetric method was used to test the inhibition activities of the complex and arsenic triiodide on the growth of the HL-60 cells in the culture medium with different concentrations
TABLE 1: The experimental data and the calculated results for powder $\mathrm{X}$-ray diffraction pattern of title complex (monoclinic system: $a=$ $1.0019 \mathrm{~nm}, b=1.5118 \mathrm{~nm}, c=2.1971 \mathrm{~nm}$, and $\beta=100.28^{\circ}$ ).

\begin{tabular}{|c|c|c|c|c|c|c|}
\hline Number & $h$ & $k$ & $l$ & $d_{\exp } / \mathrm{nm}$ & $d_{\mathrm{cal}} / \mathrm{nm}$ & $I / I_{0}$ \\
\hline 1 & 0 & 2 & 1 & 0.7132 & 0.7135 & 6.9 \\
\hline 2 & 1 & 2 & 0 & 0.6011 & 0.5999 & 0.8 \\
\hline 3 & 1 & 0 & 3 & 0.5374 & 0.5378 & 7.9 \\
\hline 4 & 0 & 1 & 4 & 0.5092 & 0.5089 & 2.5 \\
\hline 5 & -1 & 1 & 5 & 0.4088 & 0.4090 & 23.0 \\
\hline 6 & -2 & 1 & 4 & 0.3893 & 0.3882 & 7.2 \\
\hline 7 & 1 & 2 & 4 & 0.3820 & 0.3815 & 3.0 \\
\hline 8 & 0 & 2 & 5 & 0.3744 & 0.3753 & 7.3 \\
\hline 9 & 0 & 4 & 2 & 0.3570 & 0.3568 & 85.3 \\
\hline 10 & -2 & 3 & 2 & 0.3481 & 0.3484 & 5.4 \\
\hline 11 & 2 & 3 & 1 & 0.3398 & 0.3409 & 6.4 \\
\hline 12 & -3 & 1 & 0 & 0.3211 & 0.3211 & 100.0 \\
\hline 13 & 3 & 0 & 1 & 0.3159 & 0.3166 & 15.0 \\
\hline 14 & 1 & 4 & 4 & 0.2868 & 0.2872 & 12.5 \\
\hline 15 & -3 & 3 & 2 & 0.2772 & 0.2768 & 1.1 \\
\hline 16 & -2 & 5 & 1 & 0.2591 & 0.2588 & 4.1 \\
\hline 17 & 2 & 2 & 6 & 0.2533 & 0.2534 & 22.4 \\
\hline 18 & -1 & 1 & 9 & 0.2407 & 0.2405 & 6.2 \\
\hline 19 & 3 & 4 & 2 & 0.2351 & 0.2349 & 2.1 \\
\hline 20 & -2 & 4 & 7 & 0.2277 & 0.2279 & 3.3 \\
\hline 21 & -4 & 3 & 3 & 0.2217 & 0.2219 & 1.4 \\
\hline 22 & -2 & 5 & 7 & 0.2077 & 0.2076 & 36.5 \\
\hline 23 & 3 & 0 & 7 & 0.2072 & 0.2073 & 1.0 \\
\hline 24 & -3 & 6 & 3 & 0.1983 & 0.1983 & 16.8 \\
\hline 25 & -5 & 2 & 5 & 0.1868 & 0.1869 & 1.3 \\
\hline 26 & -4 & 5 & 6 & 0.1796 & 0.1794 & 20.8 \\
\hline 27 & 3 & 2 & 9 & 0.1745 & 0.1744 & 11.0 \\
\hline 28 & -5 & 3 & 7 & 0.1707 & 0.1708 & 1.2 \\
\hline 29 & -6 & 0 & 0 & 0.1644 & 0.1643 & 1.4 \\
\hline 30 & -6 & 1 & 6 & 0.1598 & 0.1598 & 4.2 \\
\hline 31 & 2 & 8 & 8 & 0.1435 & 0.1436 & 3.6 \\
\hline 32 & -6 & 6 & 6 & 0.1354 & 0.1355 & 3.9 \\
\hline 33 & 2 & 9 & 8 & 0.1337 & 0.1337 & 5.6 \\
\hline 34 & 5 & 7 & 5 & 0.1327 & 0.1328 & 2.9 \\
\hline 35 & 5 & 6 & 8 & 0.1272 & 0.1271 & 1.9 \\
\hline 36 & 7 & 6 & 2 & 0.1201 & 0.1201 & 0.8 \\
\hline
\end{tabular}

of the complex or arsenic triiodide. First, the HL-60 cells (cell suspension adjusted to $20 \times 10^{4}$ cells $/ \mathrm{mL}$ ) of logarithmic growth phase were cultured in the $100 \mu \mathrm{L}$ fresh RPMI-1640 culture medium containing $10 \%$ inactivated newborn calf serum, in 96-well plates incubator maintained at $37^{\circ} \mathrm{C}$ in a 95\% air containing 5\% carbon dioxide atmosphere at 100\% humidity. The procedure was repeated at intervals of $72 \mathrm{~h}$. The physiological salt solution with different concentrations of the complex or arsenic triiodide was added to the test culture medium, respectively. The control culture medium does contain neither the complex nor arsenic triiodide. The blank culture medium does not contain any HL-60 cell. After 


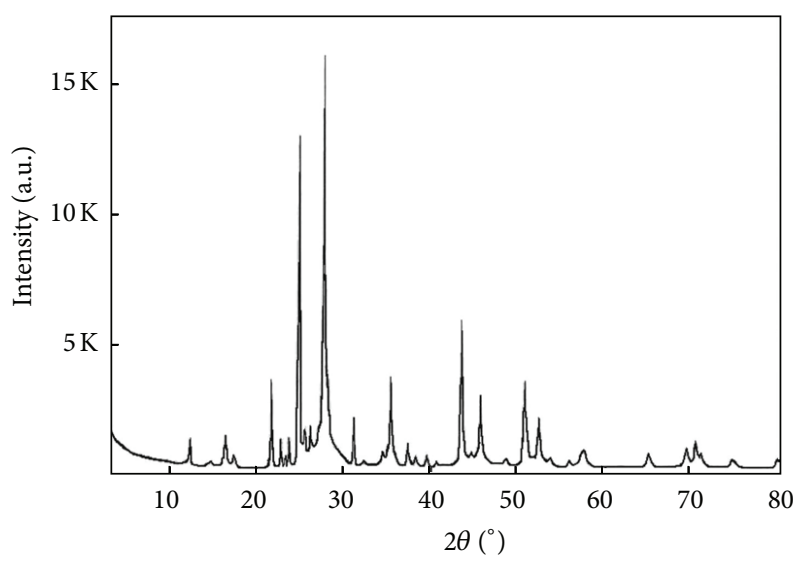

Figure 1: Powder X-ray diffraction pattern of title complex.

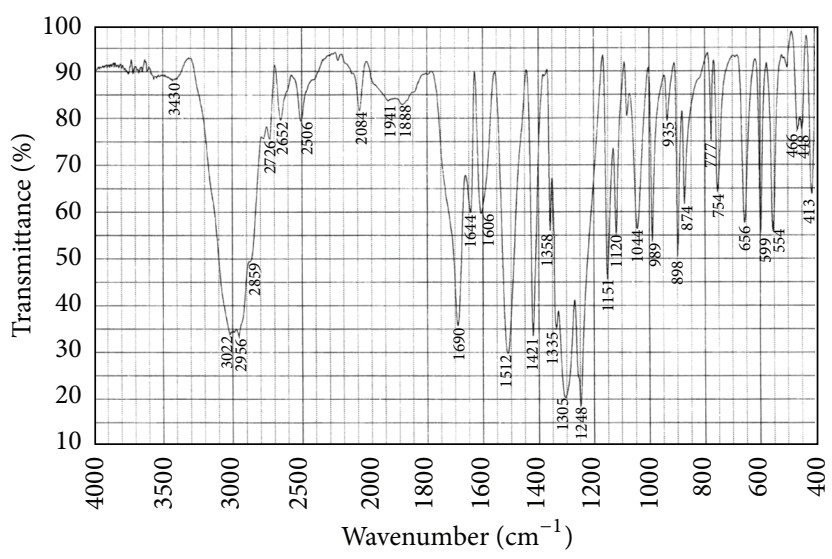

Figure 2: Infrared spectra of title complex.

3 days, a certain amount of the MTT $(5 \mu \mathrm{g} / \mathrm{mL})$ physiological salt solution was added to the various test culture media, the control culture medium, and the blank culture medium, respectively. The above culture media hold in the incubator for $4 \mathrm{~h}$. After $200 \mu \mathrm{L}$ solvent of dimethyl sulphoxide was added to $200 \mu \mathrm{L}$ of supernatant liquor from each well, the solutions were homogenized for $10 \mathrm{~min}$. Last, the inhibition activities of the complex or arsenic triiodide on the growth of the HL-60 cells in the various test culture media with different concentrations of the complex or arsenic triiodide were determined. Absorbance was measured in an automatic enzyme-mark analyzer at $530 \mathrm{~nm}$ wavelength. The inhibition rates of the complex and arsenic triiodide on the growth of the HL-60 cells in the culture medium with different concentrations of the complex and arsenic triiodide are shown in Figure 3, respectively.

\section{Results and Discussion}

All the peaks in the X-ray diffraction pattern of the resultant can be readily indexed by a set of lattice parameters according to monoclinic system, although the number of the diffraction

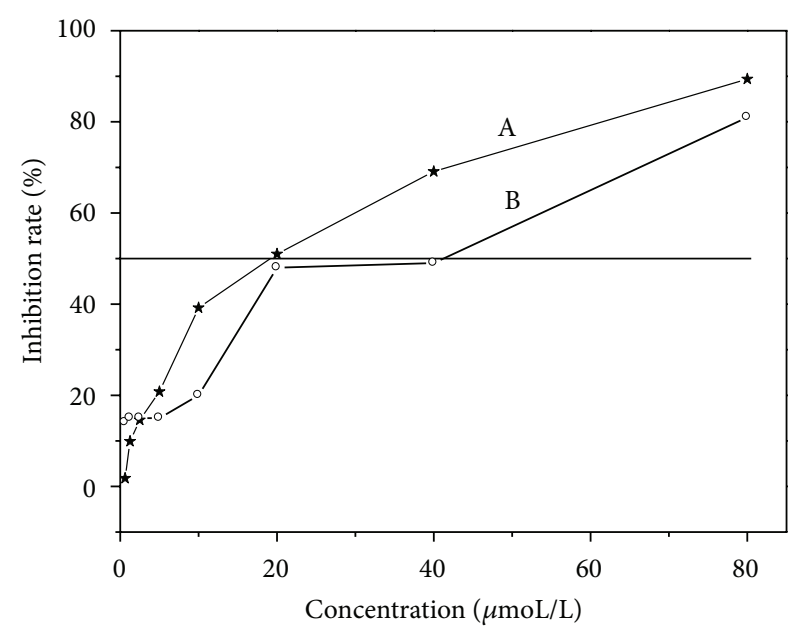

Figure 3: Inhibition rate of title complex (A) and $\mathrm{AsI}_{3}$ (B) on the growth of the HL-60 cells in the culture medium with different concentrations of $\mathrm{AsI}_{3}\left[\mathrm{OOCCH}_{2} \mathrm{CH}\left(\mathrm{NH}_{2}\right) \mathrm{CO}\right]_{2.5} \cdot 2.5 \mathrm{H}_{2} \mathrm{O}$ and $\mathrm{AsI}_{3}$.

peaks in the pattern is more. As Table 1 shows, all the relative deviations between the calculated and experimental $d_{h k l}$ are less than $0.5 \%$. This indicates that the resultant is a single-phase compound with monoclinic symmetry. The crystal structure of arsenic triiodide belongs to hexagonal system (JCPDS card 7-272). Although the crystal structure of $L$-aspartic acid also belongs to monoclinic system (JCPDS card 23-1519), the lattice parameters $(a=0.7608 \mathrm{~nm}, b=$ $0.6966 \mathrm{~nm}, c=0.5122 \mathrm{~nm}$, and $\left.\beta=99.44^{\circ}\right)$ of $L$-aspartic acid are very different from the lattice parameters $(a=1.0019 \mathrm{~nm}$, $b=1.5118 \mathrm{~nm}, c=2.1971 \mathrm{~nm}$, and $\left.\beta=100.28^{\circ}\right)$ of the resultant complex. So, the resultant must be a new complex with a formula $\mathrm{AsI}_{3}\left[\mathrm{HOOCCH}_{2} \mathrm{CH}\left(\mathrm{NH}_{2}\right) \mathrm{COOH}\right]_{2.5}$. Many complexes of arsenic are often dimer [18]. The new complex may also be a dimer and possess the formula $\mathrm{I}_{3} \mathrm{As}\left[\mathrm{HOOCCH}{ }_{2} \mathrm{CH}\left(\mathrm{NH}_{2}\right) \mathrm{COOH}\right]_{5} \mathrm{AsI}_{3}$. The dimer always possesses a bridge structure. The configuration of the complex may be $\left[\mathrm{HOOCCH}_{2} \mathrm{CH}\left(\mathrm{NH}_{2}\right) \mathrm{COOH}\right]_{2} \mathrm{AsI}_{3}[\mathrm{HOOC}$ $\left.\mathrm{CH}_{2} \mathrm{CH}\left(\mathrm{NH}_{2}\right) \mathrm{COOH}\right] \mathrm{AsI}_{3}\left[\mathrm{HOOCCH}_{2} \mathrm{CH}\left(\mathrm{NH}_{2}\right) \mathrm{COOH}\right]_{2}$.

Figure 2 shows the infrared spectrum of the resultant. There is an absorption peak at $3430 \mathrm{~cm}^{-1}$ in the infrared spectrum of the complex. Generally, the absorption peak at $3430 \mathrm{~cm}^{-1}$ can be assigned to the stretching vibration of the $\mathrm{O}-\mathrm{H}$ bond from the water molecule [19]. This shows that there may be the water molecules in the solid complex. Besides, there is also an absorption peak at $1888 \mathrm{~cm}^{-1}$ in the infrared spectrum of the complex, unlike in the infrared spectrum of aspartic acid. In particular, we have noted that the absorption peak at $1510 \mathrm{~cm}^{-1}$ is the most intense peak in the infrared spectrum of aspartic acid [20]. But the intensity of the absorption peak at $1305 \mathrm{~cm}^{-1}$ is appreciably larger than that of absorption peak at $1510 \mathrm{~cm}^{-1}$ in the infrared spectrum of the complex. The absorption peak at $1888 \mathrm{~cm}^{-1}$ in the infrared spectrum of the complex may be from the vibration 
of the carboxylic acid radical (-CO-O-OC-) group [19]. If this assignment is correct, we can understand why the absorption peak at $1305 \mathrm{~cm}^{-1}$ is such intense in the infrared spectrum of the complex. Because the vibration of the $\mathrm{C}-\mathrm{O}-\mathrm{C}$ bond in the carboxylic acid radical group can always give a very intense absorption peak at about $1300 \mathrm{~cm}^{-1}$ in the infrared spectrum [19], the presence of the absorption peaks from the various vibrations of the carboxylic acid radical group can reasonably explain the appearance of new absorption peak at $3430 \mathrm{~cm}^{-1}$ from the stretching vibration of the $\mathrm{O}-\mathrm{H}$ bond in the infrared spectrum of the solid complex. As above mentioned, the complex is prepared through a direct solid-solid reaction, and the complex does not show moisture. Therefore, the water molecules in the complex must be produced in the synthesis process of the complex. If the dehydration reaction of the aspartic acid can occur in the synthesis reaction process of the complex, the dehydration reaction must lead to formation of the water molecule and carboxylic acid radicals groups. This is just why there are the absorption peaks both from the vibration of the $\mathrm{O}-\mathrm{H}$ bond of the water molecule and from the vibrations of various bonds of the acid radical groups in the infrared spectra of the complex. On the basis of the above experimental results, we consider that the most possible formula of the dimer complex is $\left\{\mathrm{AsI}_{3}\left[\mathrm{OOCCH}_{2} \mathrm{CH}\left(\mathrm{NH}_{2}\right) \mathrm{CO}\right]_{2.5} \cdot 2.5 \mathrm{H}_{2} \mathrm{O}\right\}_{2}$.

As Figure 3 shows, the primary biological test can demonstrate that the aspartic acid complex of arsenic possesses better inhibition action on the growth of the HL-60 cells of the leukemia than the pure arsenic triiodide. To compare the concentration $\left(\mathrm{IC}_{50}\right)$ of the complex and arsenic triiodide in the test culture medium, when the inhibition rate of the complex or arsenic triiodide on the growth of the HL-60 cells is $50 \%, \mathrm{IC}_{50}$ (about $20 \mu \mathrm{mol} / \mathrm{L}$ ) of the complex is only a half of $\mathrm{IC}_{50}$ (about $40 \mu \mathrm{mol} / \mathrm{L}$ ) of arsenic triiodide. In particular, the inhibition rate of the complex on the growth of the HL60 cells increases rapidly with increasing the concentration of the complex when the concentration of the complex in test culture medium is smaller. Besides, we have also noted that the inhibition rate of the complex on the growth of the HL60 cells is always larger than that of the pure arsenic triiodide when the molar concentration of the complex and arsenic triiodide in test culture medium is the same. The difference of the complex $\mathrm{AsI}_{3}\left[\mathrm{OOCCH}_{2} \mathrm{CH}\left(\mathrm{NH}_{2}\right) \mathrm{CO}\right]_{2.5} \cdot 2.5 \mathrm{H}_{2} \mathrm{O}$ from arsenic triiodide is only that the complex contains some aspartic acid radical groups coordinated to the arsenical ion. It is not reported that the aspartic acid can possess any inhibition action on the growth of the HL-60 cells. Therefore, we can reasonably conclude that the complex formation of the aspartic acid radical groups and arsenic triiodide or the presence of the aspartic acid radical groups must play an enhanced role for the inhibition activity of arsenic triiodide on the growth of the HL-60 cells. Because even if all the complex molecules in test culture medium had been dissociated when the molar concentration of the complex and arsenic triiodide in test culture medium is the same, the concentrations of the free arsenic triiodide or arsenical ions in the test culture medium and without the complex must be the same. If the organic ligand (or aspartic acid radical group) could not play any enhanced role for the inhibition activity of arsenic triiodide on the growth of the HL-60 cells, the inhibition rate of the complex on the growth of the HL60 cells would be the same or close to that of the pure arsenic triiodide. Obviously, the experimental results show that the organic ligand or the aspartic acid radical group in the complex can play an enhanced role for the inhibition activity of arsenic triiodide on the growth of the HL- 60 cells. Although the above biological test gives only the primary results, this can still demonstrate that some organic ligands in the bioinorganic complex of arsenic can enhance the inhibition activity of arsenic on the growth of the HL-60 cells of the leukemia. Perhaps to synthesize some complexes of arsenic and the amino acids with better inhibition activity on the growth of the HL-60 cell of the leukemia will be possible.

\section{Conclusions}

New solid bioinorganic complex of the aspartic acid and arsenic triiodide can be synthesized very easily by a room temperature solid-state reaction of the aspartic acid and arsenic triiodide powders. The advantages of this synthetic method is simple and convenient operation, high yield, energy saving and environmental friendly, it is in accordance with the requirements of green chemistry. The crystal structure of the complex belongs to monoclinic system. The infrared spectrum demonstrates the complex formation between the arsenical ion and the organic ligands. The complex may be a dimer with bridge structure. The formula of the dimer complex may be $\left\{\mathrm{AsI}_{3}\left[\mathrm{OOCCH}_{2} \mathrm{CH}\left(\mathrm{NH}_{2}\right) \mathrm{CO}\right]_{2.5} \cdot 2.5 \mathrm{H}_{2} \mathrm{O}\right\}_{2}$. The oxygen atoms of two $-\mathrm{CO}$ bonds in a carboxylic acid radical (-CO-O-OC-) group will be coordinated to the two arsenical ions in two complex molecules, respectively. In this case, the $\mathrm{M}-\mathrm{OC}-\mathrm{O}-\mathrm{CO}-\mathrm{M}$ bridge links can be formed in the solid complex. The primary biological test can demonstrate that the complex possesses better inhibition activity on the growth of the HL-60 cells of the leukemia than the pure arsenic triiodide. Perhaps this may be because the aspartic acid radical groups in the complex play a certain enhanced role for the inhibition activity of arsenic triiodide on the growth of the HL-60 cells.

\section{Acknowledgments}

This work is supported by the Scientific Research Funds of Sichuan Provincial Education Department (10ZA016) and Science and Technology Bureau of Sichuan Province in China (05JY029-113).

\section{References}

[1] P. Köpf-Maier and T. Klapötke, "Antitumor activity of some organomettalic bismuth(III)thiolates," Inorganica Chimica Acta, vol. 152, no. 1, pp. 49-52, 1988.

[2] G. Cantos, C. L. Barbieri, M. Iacomini, P. A. J. Gorin, and L. R. Travassos, "Synthesis of antimony complexes of yeast mannan and mannan derivatives and their effect on Leishmania-infected macrophages," Biochemical Journal, vol. 289, no. 1, pp. 155-160, 1993. 
[3] Z. Zhang, G. Zhong, and Q. Jiang, "Biological activities of the complexes of arsenic, antimony and bismuth," Progress in Chemistry, vol. 20, no. 9, pp. 1315-1323, 2008.

[4] S. M. Mandal, A. K. Ghosh, B. R. Pati, and A. K. Das, "Detection of trivalent arsenic [As(III)] complex with DNA: a spectroscopic investigation," Toxicological and Environmental Chemistry, vol. 91, no. 2, pp. 219-224, 2009.

[5] D. C. Reis, M. C. X. Pinto, E. M. Souza-Fagundes, S. M. S. V. Wardell, J. L. Wardell, and H. Beraldo, "Antimony(III) complexes with 2-benzoylpyridine-derived thiosemicarbazones: cytotoxicity against human leukemia cell lines," European Journal of Medicinal Chemistry, vol. 45, no. 9, pp. 3904-3910, 2010.

[6] R. Bakhtiar and E.-I. Ochiai, "Pharmacological applications of inorganic complexes," General Pharmacology, vol. 32, no. 5, pp. 525-540, 1999.

[7] N. Yang and H. Sun, "Biocoordination chemistry of bismuth: recent advances," Coordination Chemistry Reviews, vol. 251, no. 17-20, pp. 2354-2366, 2007.

[8] J. Mervis, "Ancient remedy performs new tricks," Science, vol. 273, no. 5275, p. 578, 1996.

[9] Y. Jing, J. Dai, R. M. E. Chalmers-Redman, W. G. Tatton, and S. Waxman, "Arsenic trioxide selectively induces acute promyelocytic leukemia cell apoptosis via a hydrogen peroxidedependent pathway," Blood, vol. 94, no. 6, pp. 2102-2111, 1999.

[10] W. H. Miller Jr., H. M. Schipper, J. S. Lee, J. Singer, and S. Waxman, "Mechanisms of action of arsenic trioxide," Cancer Research, vol. 62, no. 14, pp. 3893-3903, 2002.

[11] P. J. Dilda and P. J. Hogg, "Arsenical-based cancer drugs," Cancer Treatment Reviews, vol. 33, no. 6, pp. 542-564, 2007.

[12] G. Q. Zhong, S. R. Luan, and Y. R. Chen, "Synthesis of arsenic(III) and antimony(III) complexes by solid phase reaction," Chinese Journal of Applied Chemistry, vol. 19, no. 9, pp. 882-885, 2002.

[13] Y. X. Yang, R. R. Jia, Y. R. Chen, J. G. Shao, X. N. Liu, and H. P. Ying, "Synthesis and biological activity of the $\mathrm{AsI}_{3}$-urotropine complex," Russian Journal of Coordination Chemistry, vol. 33, no. 9, pp. 698-703, 2007.

[14] R. R. Jia, C. P. Wu, Y. X. Yang, Y. R. Chen, J. R. Zhang, and Y. Q. Jia, "Preparation of new amino acid complex nanoparticles of bismuth and leucine," Amino Acids, vol. 28, no. 4, pp. 409-412, 2005.

[15] R. R. Jia, C. P. Wu, S. Wu, Y. X. Yang, Y. R. Chen, and Y. Q. Jia, "Synthesis and characterization of aspartic acid complexes of antimony and bismuth triiodide," Amino Acids, vol. 31, no. 1, pp. 85-90, 2006.

[16] S. Luan, Y. Zhu, and Y. Jia, "Synthesis and characterization of complex of glycyl-L-glutamine and bismuth trichloride," Protein and Peptide Letters, vol. 15, no. 10, pp. 1094-1099, 2008.

[17] J. G. Shao, Y. X. Yang, B. W. Li, L. P. Zhang, Y. R. Chen, and X. L. Liu, "Synthesis and characterization of antimony trichloride and bismuth trichloride complexes with valine," Journal of Thermal Analysis and Calorimetry, vol. 96, no. 1, pp. 277-285, 2009.

[18] N. N. Greenwood and A. Earnshaw, Chemistry of the Elements, Reed Educational and Professional, Oxford, UK, 2nd edition, 1997.

[19] K. J. Nakanshi and P. H. Solomon, Infrared Absorption Spectroscopy, Holden-Day, San Francisco, Calif, USA, 1977.

[20] A. G. Fluca, Standard Infrared Grating Spectra (No. 32815K), Sadtler Research Laboratories, 1974. 

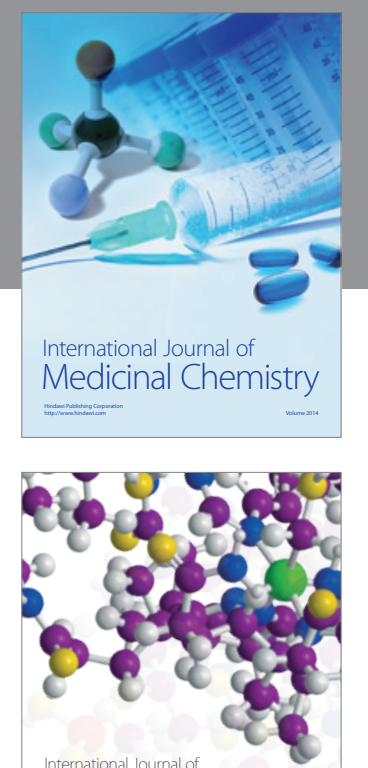

\section{Carbohydrate} Chemistry

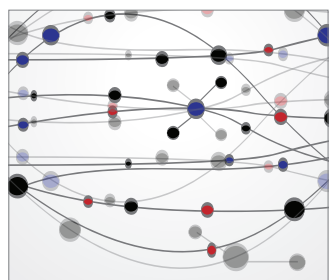

The Scientific World Journal
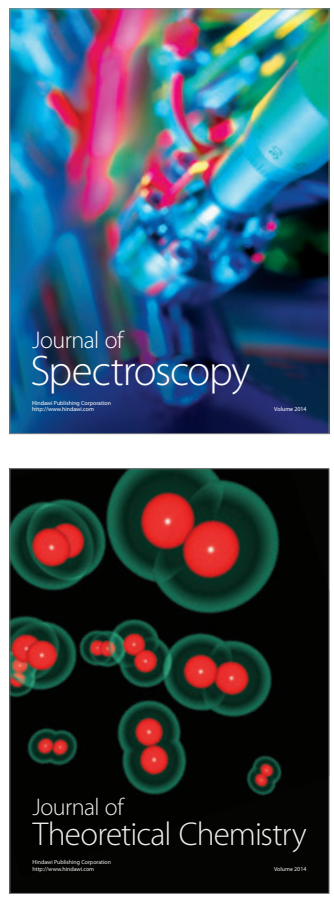
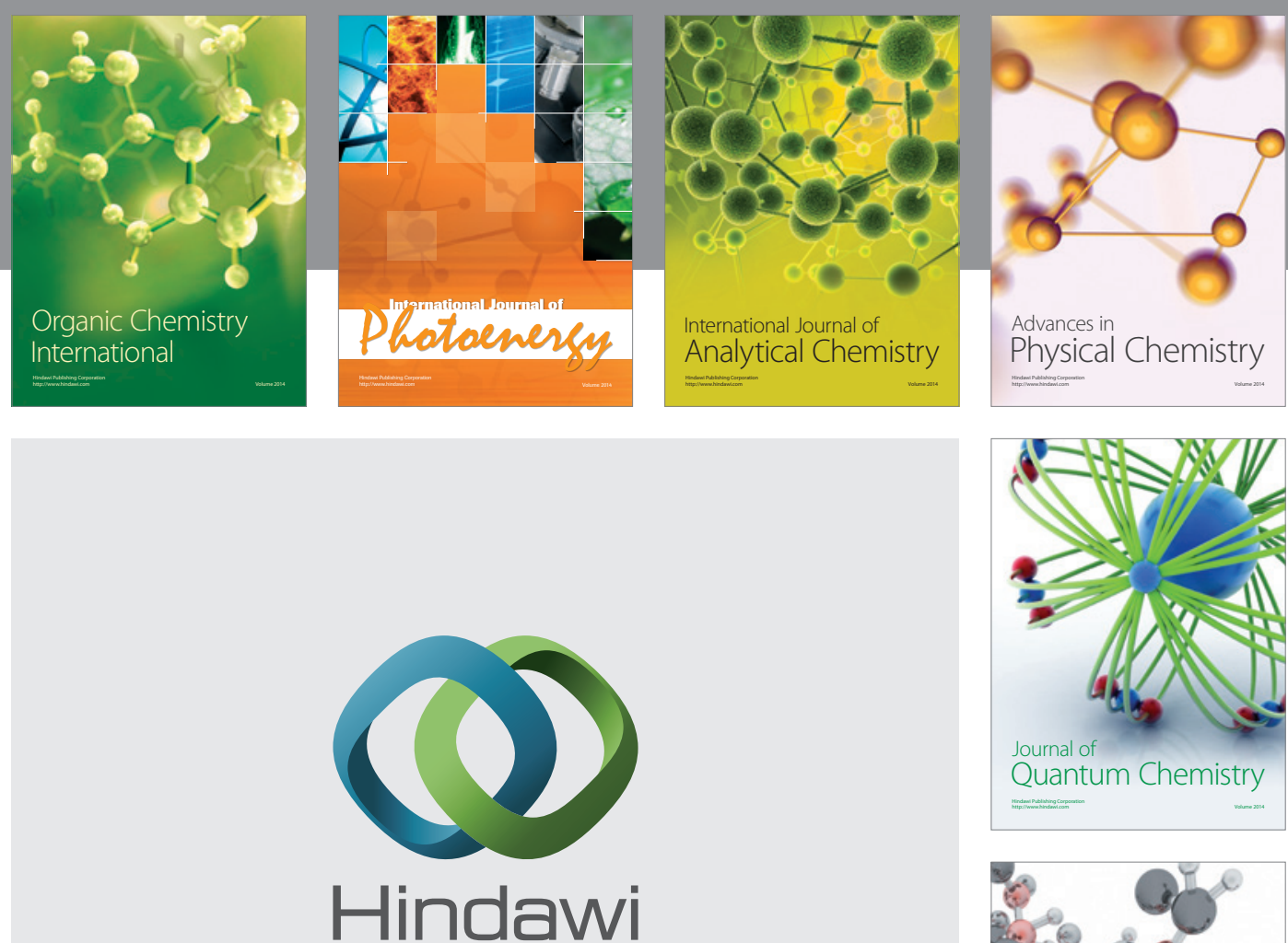

Submit your manuscripts at

http://www.hindawi.com

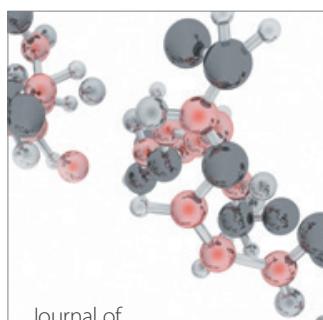

Analytical Methods

in Chemistry

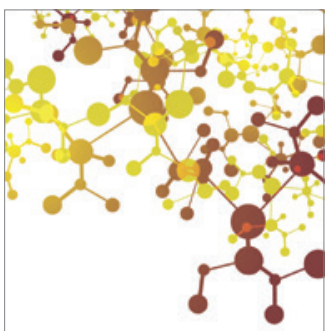

Journal of

Applied Chemistry

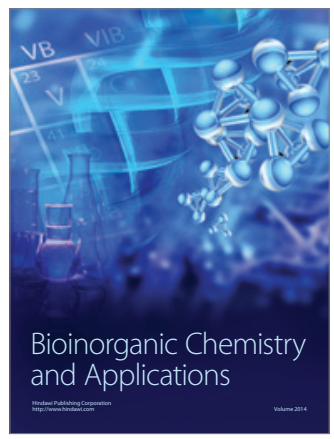

Inorganic Chemistry
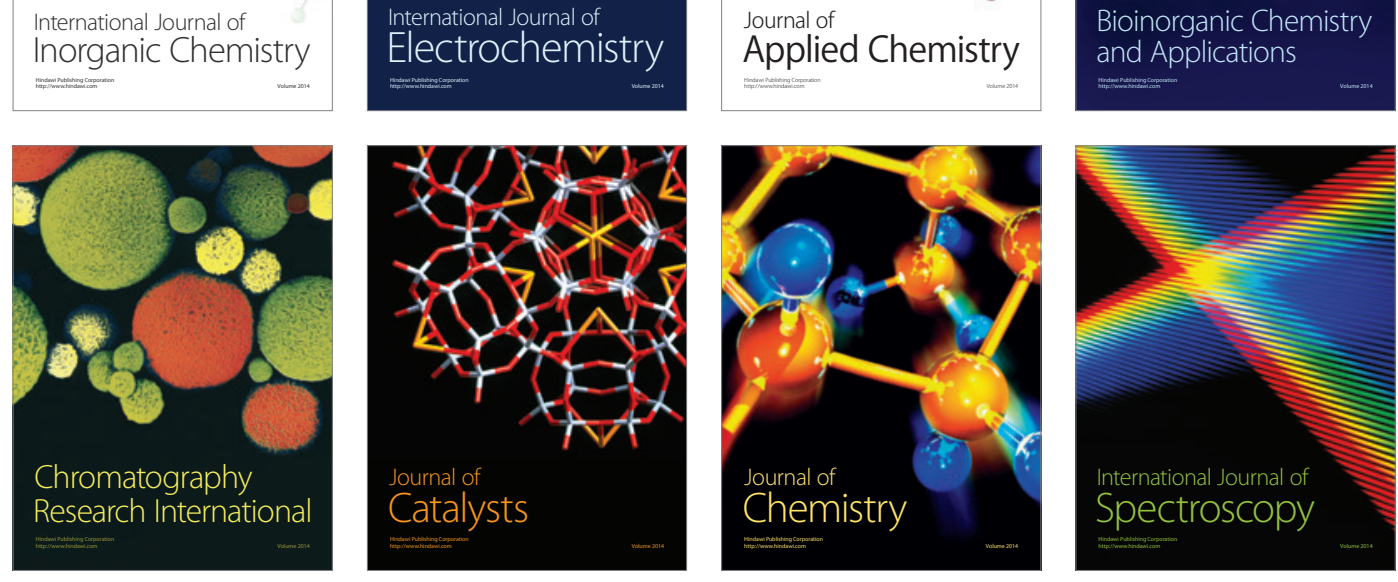